\title{
The Fear of COVID-19 Raises the Level of Depression, Anxiety and Stress through the Mediating Role of Intolerance of Uncertainty
}

\author{
Ferhat Kardaş \\ Van Yüzüncü Yıl University, Faculty of Education, Department of Guidance and Counseling, Van, Turkey
}

The COVID-19 pandemic has resulted in various psycho-social effects, including adverse effects on mental health in the general population. Many studies across different countries showed a significant increase in symptoms of fear, depression, anxiety and stress compared to the situation before the COVID-19 outbreak. Thus, it has gained more importance to examine the relationship between fear of the disease and mental health problems. This study aims to investigate the mediating role of intolerance of uncertainty in the relationship between fear of COVID-19, depression, anxiety, and stress. In this study, the sample consisted of 679 individuals. Among 679 respondents, 467 respondents were women (68.8\%) and 212 respondents were men (31.2\%). Data were collected through an online survey using the Fear of COVID-19 Scale, Intolerance of Uncertainty Scale and Depression, Anxiety and Stress Scale. Correlation analysis and structural equation modeling were used for data analysis. A significant positive relationship was observed between fear of COVID-19 and intolerance of uncertainty, depression, anxiety, and stress. All variables were found as differing significantly concerning gender, and the levels of fear were significantly higher in women than in men. Intolerance of uncertainty was found to fully mediate the relationship between fear of COVID-19 and depression, anxiety and stress. The findings obtained from this study were discussed in the light of literature findings and various suggestions were presented to researchers, mental health practitioners and policy makers.

Key words: fear of COVID-19, depression, anxiety, stress, mental health

\section{Introduction}

The world is coping with a mass pandemic once again approximately after a hundred years. For some researchers (Sher, 2020), the magnitude of the novel coronavirus (COVID-19) may be un- precedented in human history. The last comparable crisis that humanity faced was the pandemic of the Spanish Flu in 1918-19. On March 11, 2020, WHO declared the outbreak of a global pandemic after the emergence of a novel coronavirus disease in China. This declaration was followed by the emergence of

Correspondence concerning this article should be addressed to Assist Prof. Dr. Ferhat Kardaş, Van Yüzüncü YIl University, Faculty of Education, Department of Guidance and Counseling, Van, Turkey.

E-mail: kardas-90@hotmail.com

Received October 11, 2020 
various negative consequences in almost every region of the world. As known from earlier collective traumas and outbreaks, large-scale infectious disease outbreaks have a wide spectrum of psychosocial effects (Gica, Kavakli, Durduran, \& Ak, 2020). The COVID-19 outbreak overwhelmed the health care systems of most countries in a short period, led many countries to implement mass quarantines and lockdowns and brought on dramatic changes to our lives, resulting in social, economic and educational burdens at various levels. To date, about two million people have lost their lives, schools have been closed, millions of people have become unemployed and social life in many countries has come to a standstill. All these problems, as expected, also made the pandemic a global mental health issue. The coronavirus disease is continuing its spread throughout the world and number of coronavirus related deaths continues to rise dramatically. In Turkey, while this study was conducted, the number COVID-19-related death toll was reported by the Ministry of Health $(\mathrm{MoH}, 2020)$ as below 100 in September and October, over 100 in November and over 200 in December. As of December 31,2020 , the total number of deaths in the country was reported as 20,881 and the total number of cases as 2,208,652. Since the pandemic process is very likely to continue and cause prolonged social isolation and severe economic impact, the health professionals have expressed their concerns about the potential negative impact of the outbreak on mental health (Ornell, Schuch, Sordi, \& Kessler, 2020). According to some researchers (Sher, 2020), the psychological impact of the pandemic is expected to persist for years and long-lasting effects on mental health are very likely to be reported (Fitzpatrick, Harris, \& Drawve, 2020). Taking all these issues into consideration, it is crucial to establish mental health policies to attach more attention to public mental health and help people through this challenging time (Xiong et al., 2020). As a result of these efforts, various studies have investigated the possible negative impact of COVID-19 on mental health.

The COVID-19 pandemic leads to various mental health problems. An extremely high rate of infection and relatively high mortality (Ahorsu et al., 2020), besides the unpredictable consequences, uncertainties, lack of information or misinformation about the outbreak (Zandifar \& Badrfam, 2020) along with mass lockdowns and economic recession (Xiong et al., 2020), have led to the rise of fear, feeling of uncertainty, depression, anxiety, traumatic stress and some other mental health problems. In a review (Xiong et al., 2020), which aims to examine the psychological impact of the pandemic on the general population, participants showed symptoms of depression, anxiety, PTSD and psychological distress at high rates. Similarly, some other studies showed that almost $35 \%$ of the participants reported experiencing psychological distress (Qiu et al., 2020) and that anxiety and depression symptoms were widely prevalent among participants (Huang \& Zhao, 2020). These studies showed that depression, anxiety and stress were common mental health problems arising in times of the COVID-19 pandemic. Accordingly, identifying concepts that are common in depression and anxiety may help examine trans-diagnostic vulnerabilities and provide a basis to develop treatment protocols (Carleton et al., 2012).

One of the factors resulting in high levels of depression, anxiety and stress during the outbreak is fear, such as fear of being infected with COVID-19, or fear of infecting loved ones (Bitan et al., 2020). Thus, with the emergence of the pandemic, the concept of "fear of coronavirus" has started to be studied in the mental health field (Mertens et al., 2020), and some researchers suggest that the level 
of fear of the COVID-19 should be assessed to decide whether prevention and support programs are necessary and to determine the most vulnerable groups as the target population of intervention studies (Pakpour \& Griffiths, 2020). In a study conducted by Pierce et al. (2020) on 17,452 participants from the UK, the general health conditions of individuals before and during the pandemic process were compared. The findings showed that clinically significant levels of mental distress rose from $18.9 \%$ in $2018-19$ to $27.3 \%$ in April 2020 . It was also reported that general health questionnaire scores also increased over this time, from 11.5 in 2018-19 to 12.6 in April 2020. This change was reported as higher than expected when compared to general trends between 2014 and 2018. General health scores were highest among 18-24-year-olds, 25-34-yearolds, women and people living with young children. In another longitudinal cohort study (Shanahan et al., 2020), perceived stress, internalizing symptoms, anger, COVID-19-related stressors, and coping strategies of participants were measured during the pandemic when they were aged 22 years, and previous distress and stressors were measured before COVID-19 when they were aged 20 years. An increase in the levels of perceived stress and anger were reported among participants compared to pre-pandemic stress and anger levels. Pre-pandemic distress, during-pandemic economic and psychosocial stressors and pre-pandemic social stressors were associated with increased emotional distress. In another study, evidence was reported pointing out the high levels of fear worldwide (Knipe et al., 2020). In some cases, the COVID-19 pandemic and the fear related to it may contribute to suicide (Mamun \& Griffiths, 2020; Sher, 2020) and more anxiety, depression, and self-harm (Dsouza, Quadros, Hyderabadwala, \& Mamun, 2020).

Another coexisting problem that is commonly studied during pandemics and mass traumatic events is the concept of intolerance of uncertainty. The current pandemic has resulted in significant uncertainty for the general public (Rettie \& Daniels, 2021). A higher level of intolerance of uncertainty is generally associated with many mental health problems and disorders (Grupe \& Nitschke, 2013; Hong \& Cheung, 2015; Hollingsworth et al., 2018; Mertens et al., 2020; Rettie \& Daniels, 2021). Increasing level of intolerance of uncertainty may play a role in the development and maintenance of psychosomatic complaints (Gica et al., 2020) and is considered a trans-diagnostic vulnerability factor for psychopathology (Carleton, 2016). The concept of intolerance of uncertainty has been defined as a negative response to ambiguity (Freeston et al., 1994), as the excessive tendency of an individual to consider occurrence of a negative event as unacceptable in spite of the slight probability of its occurrence (Dugas, Gosselin, \& Ladouceur, 2001), and as the dispositional fear underlying emotional difficulties which results in anxiety when perceiving the unknown situations as severe (Fergus, 2013). The level of uncertainty during the pandemic may increase because of many factors, including not knowing when the threat of the pandemic will end (Rettie \& Daniels, 2021) and uncertainty itself may be maintaining anxiety by increasing the perceived threat as more severe (Dugaset et al., 2005; Dugas, Marchand, \& Ladouceur, 2005). Individuals displaying high levels of intolerance of uncertainty are likely to believe that they lack the necessary coping skills to effectively overcome the threatening situations that may cause some emotional disorders and discomfort (Holaway, Heimberg, \& Coles, 2006) and may find many things in their life intolerable (Dugas et al., 2001). They are also worrying by considering the occurrence of a negative event, particularly future negative events, as unacceptable and threatening (Carleton et al., 2007; Shihata et al., 2016). 
When the literature is examined, feelings of fear, depression, anxiety, stress and intolerance of uncertainty are intensely experienced during the pandemic process. Nowadays, fear of COVID-19 is widely studied in the field of mental health. This fear may cause depression, anxiety, and stress depending on its intensity. As in other collective traumatic experiences, the epidemic process also causes an intense feeling of uncertainty in the lives of individuals. Factors, such as during-pandemic stressors, anxiety for the future, quarantine processes, mass lockdowns, and the rise in unemployment, also contribute to more uncertainty.

Various studies have been conducted to investigate the relationships between these variables. Satici et al. (2020) investigated the relationship between intolerance of uncertainty, fear of COVID-19, rumination and mental well-being. The authors found an indirect relationship between intolerance of uncertainty and mental well-being and this relationship was partially mediated by rumination and fear of COVID-19. They used fear of COVID-19 as a mediating variable and mental well-being as a dependent variable. They hypothesized that intolerance of uncertainty affects the mental well-being through the mediating role of fear of COVID-19. In mediation analysis, the mediating variable explains the underlying relationship between independent and dependent variables. This relationship may be partially or fully mediated by intervening variables. Finding this variable in social sciences is critical, especially for the development and application of treatment and prevention programs (Mackinnon, 2015). Thus, setting the variable of intolerance of uncertainty rather than the feeling of fear as a mediator may provide a more proper base for intervening with the psychological impact of any outbreak. The feeling of fear springs in reaction to a perceived threat and alerts the individual to take measures against the danger. It is more difficult to work with this feeling with a preventive approach. Compared to fear, intolerance of uncertainty is a more persistent emotional state and the level of tolerance of uncertain situations can be built more easily through appropriate interventions. The research findings show that there are cognitive treatments aimed to increase the level of tolerance to the unavoidable uncertainties in our lives and the level of intolerance may decrease with appropriate interventions (Kendall et al., 2020; Robichaud \& Dugas, 2006).

Taken together, in this study it is hypothesized that the fear of COVID-19 and intolerance of uncertainty have significant relationships with depression, anxiety and stress and that intolerance of uncertainty has a mediating role in this relationship. Thus, this study aims to test a mediation model that is proposed based on the literature findings to explain this relationship. Bakioglu, Korkmaz and Ercan (2020) investigated the mediating role of intolerance of uncertainty, depression, anxiety, and stress in the relationship between the fear of COVID-19 and positivity and found a mediating role among those variables. The data of this study were collected in March and April 2020. The first COVID-19 case was reported in Turkey in March. At that time, the images of people who fell in the middle of the streets in China were broadcasted on TV and social media. This situation may have caused people to react with more fear in the early days of the pandemic. Thus, this study differs in two aspects. Firstly, the present study directly explores the relationship between two variables with a proposed mediation model. Secondly, many studies were conducted mostly during the first days of the pandemic when the level of fear was highest and knowledge about the nature of the disease was at its lowest level. In this context, the level of fear measured in these early days may decrease 
dramatically in later days. In this respect, this study can provide a comparison of the current level of fear towards the pandemic compared to the fear in early periods of the outbreak.

\section{Methods}

\section{Participants}

This research was conducted in September 2020 while the COVID-19 outbreak was intensifying all over the world. This cross-sectional study was conducted from September 15 until September 30, 2020. The target population was the general population in Turkey above the age of 18 and participants were at least high school graduates. The sample consisted of 679 individuals; 467 were women $(68.8 \%)$ and 212 were men (31.2\%). The age of the participants ranged between 18-61 $\left(M_{\text {age }}=26.7, S D=7.8\right)$. Of the participants, $25.5 \%$ were married and $74.5 \%$ were single. Concerning the education level, among the participants, 9.6\% had a high school degree and, $78.6 \%$ were undergraduate students or had a university degree, $11.8 \%$ had a master's degree. Only $8 \%$ of participants reported that they were infected with COVID-19 disease. The participants were recruited by a webbased online questionnaire. They provided informed consent before data collection. All survey questions were required to be filled in. The survey was distributed through methods of personal messaging applications, different social media sites and internet forums. The ethical approval of using the data collection tools to conduct this study was obtained from the ethics committee of the university with the number of 85157263-604.01.02-E.72419.

\section{Data Collection Tools}

Depression, Anxiety and Stress Scale (DAS 21): This scale was developed by Lovibond and Lovibond (1995) to assess the level of depression, anxiety and stress. The scale consists of 21 items and has three dimensions of depression, anxiety and stress. It is a Likerttype scale with 4-point scoring [range from 0 (never) to 3 (always)]. An example item is "In the last week, I realized that I did not experience any positive feelings". In this study, the adapted Turkish version of the scale (Saricam, 2018) was used. The Cronbach's alpha internal consistency coefficient of Turkish form was $\alpha=.87$ for the depression subscale, $\alpha=$ .85 for the anxiety subscale, and $\alpha=.81$ stress subscale for the clinical sample. In this study, these values were .78 for depression, .70 for anxiety and .74 for stress subscales.

Intolerance of Uncertainty Scale: The scale was developed by Carleton, Norton, \& Asmundson (2007) to assess reactions to uncertainty and ambiguous situations. The scale consists of 12 items with a two-dimensional structure. The scale is a Likert-type scale with a scoring of 5-points (1 as "not at all characteristic of me", 5 as "entirely characteristic of me"). An example item is "I always want to know what the future will bring me". The Turkish form, which was adapted by Saricam et al. (2014), was used in this research. Factor loadings ranged from .55 to .87. Cronbach's alpha internal consistency coefficient was .88 for the overall scale, .84 for the prospective anxiety subscale, and .77 for the inhibitory anxiety subscale. In this study Cronbach's alpha internal consistency was .87 for the overall scale.

The Fear of COVID-19 Scale (FCV-19S): The scale was developed by Ahorsu et al. (2020) to assess the fear of coronavirus disease. FCV-19S is a one-dimensional scale consisting of seven items with 5-point Likert type scoring [ranging from 1 (strongly disagree) to 5 (strongly agree)]. An example item is, "I get nervous or worried when I see stories and news about the coronavirus on social me- 
dia." The Turkish form of the scale, which was adapted by Bakioglu et al. (2020), was used in this study. The factor loads ranged from .73 to .82. Cronbach's alpha internal consistency coefficient was .88 in the adaptation study and .83 for the current study.

\section{Data Analysis}

In the preliminary analysis, univariate normality, homogeneity and linearity assumptions were examined. Then, the assumptions of multi-variables statistics, like multivariate normality and multicollinearity, were examined. The characteristics of the participants were reported using descriptive statistics. The internal consistency values of each measurement tool were analyzed and the measurement model was tested. Relationships among variables were examined using Pearson Product Moment Coefficient analysis, the proposed model was tested with structural equation modeling (SEM), and mediation analysis was performed using the SEM analysis.

\section{Results}

\section{Descriptive Statistics and T-Test Results}

Although fear of COVID-19 $\left(t_{(679)}=4.39, p<\right.$ $.01)$, intolerance of uncertainty $\left(t_{(679)}=3.62\right.$, $p<.05)$, depression $\left(t_{(679)}=3.97, p<.01\right)$, anxiety $\left(t_{(679)}=4.37, p<.01\right)$ and stress $\left(t_{(679)}=\right.$ $4.67, p<.01)$ significantly differed concerning gender, the effect sizes were small to moderate (Table 1).

One of the aims of this study was to compare the findings of the current study with the findings of the research that Bakioglu et al. (2020) conducted in Turkey in the early days of the pandemic. Within this framework, the values of the study that Bakioglu et al. (2020) conducted using the same measurement tools were analyzed. Accordingly, in the mentioned study, the fear of COVID-19 score was found as $19.44(S D=6.07)$, depression score as $6.26(S D=4.53)$, anxiety score as 3.34 $(S D=3.37)$, stress score as $5.99(S D=4.21)$, inhibitory anxiety score as $16.03(S D=5.13)$, and prospective anxiety score as 23.88 (SD =

Table 1 Descriptive statistics and t-test results

\begin{tabular}{|c|c|c|c|c|c|c|c|}
\hline Variable & Gender & $n$ & $M$ & $S D$ & $t$ & $p$ & Cohen's $d$ \\
\hline \multirow{2}{*}{ Depression } & Women & 467 & 6.74 & 5.14 & \multirow{2}{*}{3.97} & \multirow{2}{*}{.000} & \multirow{2}{*}{.32} \\
\hline & Men & 212 & 5.12 & 4.81 & & & \\
\hline \multirow{2}{*}{ Anxiety } & Women & 467 & 4.77 & 4.01 & \multirow{2}{*}{4.37} & \multirow{2}{*}{.000} & \multirow{2}{*}{.37} \\
\hline & Men & 212 & 3.38 & 3.40 & & & \\
\hline \multirow{2}{*}{ Stress } & Women & 467 & 7.43 & 4.59 & \multirow{2}{*}{4.67} & \multirow{2}{*}{.000} & \multirow{2}{*}{.39} \\
\hline & Men & 212 & 5.72 & 3.99 & & & \\
\hline \multirow{2}{*}{ Int. of Uncertainty } & Women & 467 & 41.65 & 9.72 & \multirow{2}{*}{3.62} & \multirow{2}{*}{.000} & \multirow{2}{*}{.32} \\
\hline & Men & 212 & 38.85 & 9.13 & & & \\
\hline \multirow{2}{*}{ Fear of COVID-19 } & Women & 467 & 16.61 & 6.09 & \multirow{2}{*}{4.39} & \multirow{2}{*}{.000} & \multirow{2}{*}{.37} \\
\hline & Men & 212 & 14.47 & 5.37 & & & \\
\hline
\end{tabular}

Note. M - Mean; SD - Standard deviation 
Table 2 Means, standard deviations and relationships among variables

\begin{tabular}{lrrrrcccc}
\hline Variables & $M$ & $S D$ & 1 & 2 & 3 & 4 & 5 & 6 \\
\hline 1. Fear of COVID-19 & 15.94 & 5.95 & - & $.128^{* *}$ & $.263^{* *}$ & $.148^{* *}$ & $.265^{* *}$ & $.261^{* *}$ \\
2. Depression & 6.24 & 5.09 & - & - & $.703^{* *}$ & $.779^{* *}$ & $.471^{* *}$ & $.429^{* *}$ \\
3. Anxiety & 4.33 & 3.88 & - & - & - & $.739^{* *}$ & $.438^{* *}$ & $.387^{* *}$ \\
4. Stress & 6.90 & 4.48 & - & - & - & - & $.473^{* *}$ & $.463^{* *}$ \\
5. Inhibitory Anxiety & 16.52 & 5.25 & - & - & - & - & - & $.641^{* *}$ \\
6. Prospective Anxiety & 24.25 & 5.37 & - & - & - & - & - \\
\hline
\end{tabular}

5.15). The scores in the present study were $15.94(S D=5.9$ ) for fear of COVID-19, 6.24 $(S D=5)$ for depression, 4.33 for anxiety $(S D=$ 3.8), 6.90 for stress $(S D=4.4), 15.52(S D=5.2)$ for inhibitory anxiety, and $24.25(S D=5.3)$ for prospective anxiety in this research (Table 2).

\section{Correlation Analysis}

The relationships between variables were calculated using Pearson's correlation. As seen in Table 2, there was a significant positive relationship among all variables at the 0.01 level (2-tailed). Specifically, there was a positive relationship of fear of COVID-19 with depression $(r=.12, p<.01)$, anxiety $(r=.45, p<.01)$, stress $(r=.51, p<.01)$, inhibitory anxiety $(r=$ $.26, p<.01)$ and prospective anxiety $(r=.26$, $p<.01$ ). All other variables also have a significant positive relationship with each other at different levels.

\section{Results of Measurement Model}

Before testing the structural model with SEM, the measurement model was tested as follows: DAS was included as one latent variable with three observed variables (depression, anxiety and stress dimensions), fear of COVID-19 with seven observed variables, and intolerance of uncertainty with two observed variables (prospective anxiety and inhibitory anxiety dimensions). Fit indices were as follows: $\chi^{2}$ /SD: 4.29, RMSEA: .070, NFI: .97, CFI: .97, IFI: .97, GFI: .97, and SRMR: .052. These fit values of this measurement model can be said as good enough to test the suggested structural model.

\section{The Structural Equation Modeling with LISREL}

The mediation analysis was performed using the SEM Analysis. In the first step, three different hypothetical models that are suggested based on related literature were tested. The maximum likelihood method was used for estimation. The results of these models are shown in Figure 1, Figure 2, and Figure 3.

As shown in Figure 1, the fear of COVID-19 has a significant effect on depression, anxiety, and stress. The fit indices of these models were as follows: $\chi^{2} / \mathrm{SD}: 5.80$, RMSEA: .084, SRMR: .057, NFI: .96, CFI: .97, IFI: .97, GFI: .95 and the values indicated that although $\chi^{2} / S D$ was above 4 , because it is sensitive to a high number of sample, the proposed model had acceptable fit values. After testing this model, the intolerance of the uncertainty variable was entered into the model as a mediator. The model is shown in Figure 2.

As shown in Figure 2, when the intolerance of uncertainty variable enters the model as a mediator, the path from fear of COVID-19 


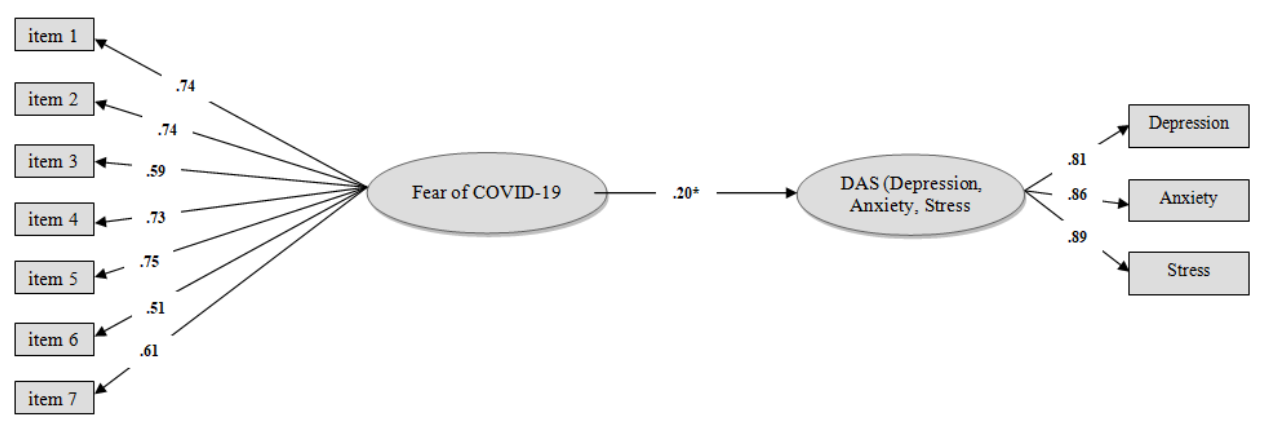

Figure 1 Model 1 (The presented values are standardized coefficients. ${ }^{*} p<.05$ ).

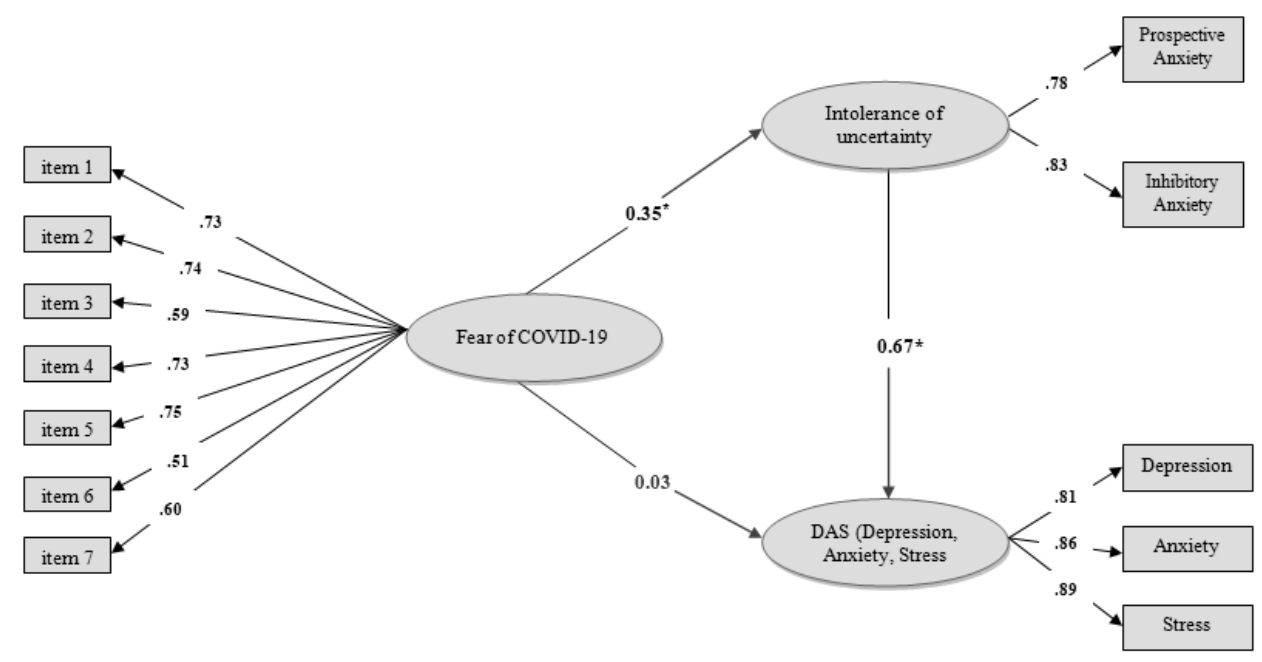

Figure 2 Model 2 (The presented values are standardized coefficients. ${ }^{*} p<.05$ ).

to DAS, which was .20 in the previous model, becomes insignificant. The standardized coefficient between fear of COVID-19 and intolerance of uncertainty is $B=.35$, and between intolerance and DAS is $B=.67$. The ultimate proposed model, which was suggested based on the literature, is shown in Figure 3.

The fit indices of the ultimate model were reported as follows: $\chi^{2} / \mathrm{SD}: 4.22$, RMSEA: .069, SRMR: .052, NFI: .97, CFI: .97, IFI: .97,
GFI: .95. These values suggest that the proposed model has good fit values. A chi-square difference test was conducted for a comparison between model 2 and model 3. The chi-square value of model 3 was 211.48 and $d f$ value was 50 , and the same values were calculated as 210.89 and 49 for model 2. The $p$-value was calculated as 0.44 after performing the chi-square difference test. This finding indicates that there is no significant difference 
between the two models, and adding a direct path between fear of COVID-19 and DAS variables does not improve the model. Thus, the smaller ultimate model 3 with more degree of freedom was accepted by eliminating the insignificant direct pathway from model 2 . The total, direct and indirect effects of fear of COVID-19 on depression, anxiety, and stress are presented in Table 3.

The model suggests that fear of COVID-19 has a significant direct effect on the intolerance of uncertainty $(b=.34, t=7.39, p<.01)$ and intolerance of uncertainty has a significant direct effect on DAS $(B=.66, t=13.72$, $p<.01)$. When the intolerance of uncertainty variables entered the model as a mediator, the total standardized indirect effect of fear of COVID-19 on DAS was found as $B=.22, t=$ $6.69, p<.01$.

\section{Discussion}

This study investigated the potential effects of the novel coronavirus outbreak on mental health by examining the indirect effects of COVID-19-related fear through intolerance of uncertainty, on depression, anxiety, and stress. Based on the findings in the literature, we hypothesized that fear of a novel coronavirus pandemic will have an indirect effect on

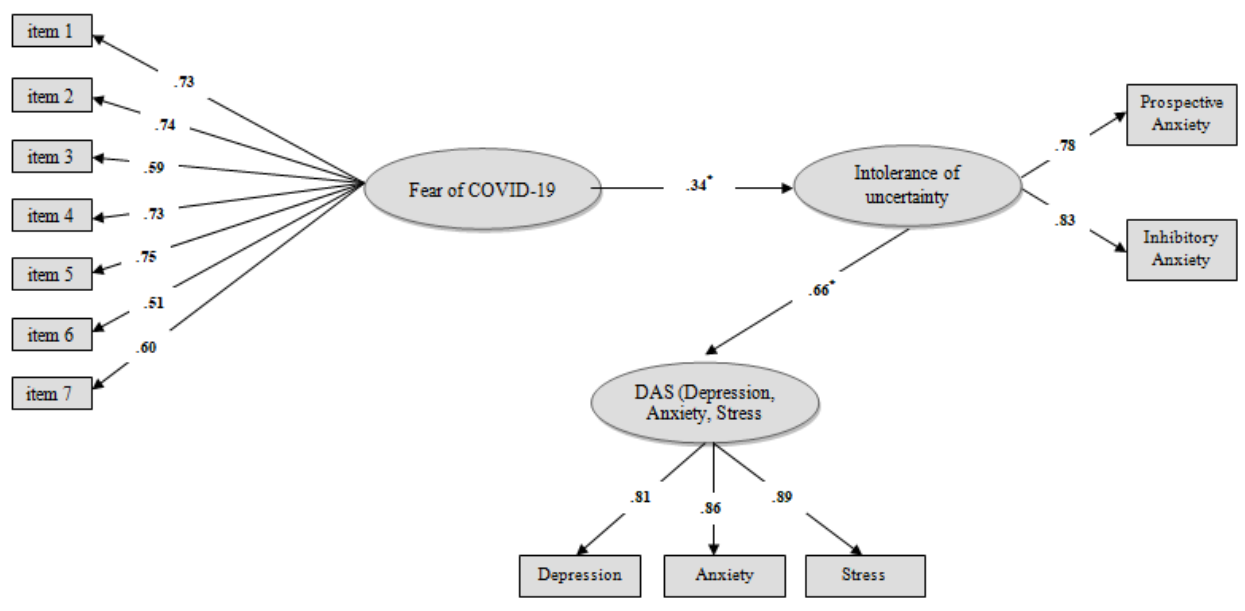

Figure 3 The ultimate model (The presented values are standardized coefficients. ${ }^{*} p<.05$ ).

Table 3 Indirect effects of fear of COVID-19 on DAS with structural equation modeling

\begin{tabular}{lrr}
\hline Structural Relations & $(8)$ & \multicolumn{1}{c}{$t$} \\
\hline Standardized Effects & & \\
Fear of COVID-19 $\rightarrow$ Intolerance of uncertainty & .34 & 7.39 \\
Intolerance of uncertainty $\rightarrow$ DAS & .66 & 13.72 \\
Standardized Indirect Effects & & \\
$\quad$ The fear of COVID-19 $\rightarrow$ Intolerance of uncertainty $\rightarrow$ DAS & .22 & 6.69 \\
\hline Note. $p<.01$ & &
\end{tabular}

Note. $p<.01$ 
depression, anxiety and stress and intolerance of uncertainty will mediate this relationship. We examined this hypothesis with the SEM analysis in this study.

We investigated whether the levels of COVID-19-related fear, intolerance of uncertainty and depression, anxiety, and stress differ in terms of gender. The score of all variables was higher in women than men, which may suggest that women are more vulnerable to fear, depression, stress, anxiety and intolerance of uncertainty during the pandemic and gender may be a risk factor, which should be considered in such times. However, the effect size of this difference was found to be at a small to moderate level. Although there is a significant difference between variables by gender, the effect size for this difference is not large. This situation reveals that the mentioned gender differences should be approached more carefully and this effect should be examined in other studies. This finding shows consistency with the results of some studies examining the psychological impact of the outbreak on the general population. In many studies (Bakioglu et al., 2020; Maza et al., 2020; Parlapani et al., 2020; Solomou et al., 2020; Xiong et al. 2020; Wang, Tang, \& Wei, 2020), female gender was found as a risk for the development of more severe depression, anxiety and stress symptoms during the pandemic. Since it was determined that mental health difficulties were reported to rise during the pandemic, particularly in more vulnerable groups (Rettie \& Daniels, 2021), these are important findings for designating the female gender as a risk factor during pandemics and mass traumas. There is no common agreement about the interpretation of the findings concerning gender in the literature. The findings of this study may also have some alternative explanations. In a study (Bitan et al., 2020) conducted in Israel, the score of COVID-19-related fear of women was higher than men, and this dif- ference was suggested to be associated with gender differences in sensitivity to stress. Socio-economic and educational issues may be another reason for these differences. In a study (Effati-Daryani et al., 2020) conducted on depression, anxiety and stress levels of pregnant women in Iran during the epidemic, variables such as spouse's education level, spouse's support, marital life satisfaction and household income sufficiency were reported as predictors of depression, anxiety and stress. In a similar study (Thayer \& Gildner, 2020) conducted in the USA, COVID-19-related financial stress was found as a predictor of depression among pregnant women. These findings suggest that the results of gender differences in this study may also be related to the educational and socio-economic conditions of women. In addition, Wang et al. (2020) found that most of the participants attending a study on COVID-19 expressed concerns related to their family members getting sick. Thus, depression, anxiety, stress and fear level of women may be, in part, related to the protection of their children and other family members from all possible effects of the outbreak. Last, it may be related to some cultural patterns and gender roles attributed to women in a society that result in women thinking of themselves as more vulnerable to fear, depression, anxiety and stress during traumatic events.

As stated in the introduction section, one of the aims of this research was to compare the mental health status at the beginning of the pandemic with subsequent periods, especially in the context of fear of COVID-19. The findings of this comparison suggest that there is a decrease in the level of fear (approximately $20 \%$ decrease) and an increase in levels of anxiety (approximately 30\% increase) and stress (approximately 15\% increase). There were no critical changes in the levels of intolerance of uncertainty and depression. These 
changes in scores do not represent a statistical difference. Therefore, it does not seem possible to make certain interpretations based on these comparisons. These changes may arise from the difference in the sample, apart from the hypothesis proposed in this study. Given this limitation, there may be many inferences from these results. However, in general, it seems that the fear of COVID-19 decreased, anxiety and stress increased compared to early periods of the pandemic. Although there are small increases in the level of intolerance of uncertainty scores, these changes do not appear to be significant concerning rates of change. This finding may contribute to the assumption underlying the model proposed in this study that feeling of fear against the outbreak may change in later periods and intolerance of uncertainty is more stable than the feeling of fear. One inference is that the feeling of fear of the outbreak may decrease over time without any psychological intervention and intolerance of uncertainty may necessitate systematic interventions for the decrease. Thus, setting the latter variable as the mediating variable makes more sense, in terms of intervention studies.

Another main finding of this research is that there are significant positive relations among all variables, and the relationship between fear of COVID-19 and depression, anxiety, and stress is fully mediated by intolerance of uncertainty. In some other studies, positive relationships were determined between fear of COVID-19 and intolerance of uncertainty, depression, anxiety and stress variables (Bakioglu et al., 2020; Harper et al., 2020; Satici et al., 2020). Moreover, Gica et al. (2020) examined the mediating role of intolerance of uncertainty between perceived COVID-19 threat and personal health and found that intolerance of uncertainty partially mediated this relationship, which is consistent with this research. Taken together, these findings are establishing the idea that collective infectious diseases and pandemics may be traumatic for some people and lead to psychological distress (Boyraz \& Legros, 2020; Mihashi et al., 2009). In fact, this is an important finding, especially in times of outbreaks and collective traumas. It is argued that both individuals and communities may commonly experience feelings of hopelessness, despair, grief, bereavement, and loss of purpose because of pandemics (Levin, 2019). The collective outbreaks are generally destroying our assumptions towards life and the future. In such times, it becomes difficult to make plans even for the coming days. Uncertainty makes life more difficult in various areas. Thus, one of the most important negative impacts of the COVID-19 pandemic on mental health is the feeling of uncertainty that it brings. Studies examining the reactions of individuals to previous outbreaks revealed that some psychological vulnerability factors may contribute to fear, including intolerance of uncertainty and perceived vulnerability to disease (Taylor, 2019). Although there is a vaccine for the disease, the number of deaths continues to increase, and it is not known when the outbreak will end. In Turkey, at the time when this study was conducted, the vaccination process had not started yet. On the other hand, it has been declared by the ministry of health that healthcare workers will be vaccinated first. Due to the limited number of vaccine doses available, it is not yet known when all of the population will be vaccinated. For these reasons, the social, psychological, economic burden of the pandemic on people is rising day by day, contributing to feelings of uncertainty.

There are some suggestions to researchers, practitioners working on mental health issues and policymakers working in different fields. Firstly, this study has revealed that there is a significant difference between individuals' levels of fear during the first days of the pan- 
demic and six months later. An important decrease was reported in individuals' scores of COVID-19-related fear. Similarly, it has been revealed that there is an important increase in the anxiety and stress scores of individuals. These current results indicate that, especially during the early days of the course of the epidemic, the feeling of fear is more intense and may decrease later. This situation reveals the need for longitudinal research on the subject of the epidemic process. Although there are studies that comparatively reveal the pre-epidemic, during-epidemic and post-epidemic mental health conditions, to our knowledge, there is not any research that performed this measurement during the epidemic process. Second, there are groups that are more vulnerable in times of pandemics, including women, and they need to receive more attention in planning and intervention studies (Qiu et al., 2020). Third, it is understood well by almost all governments that this process urgently needs to establish good coordination and planning for effective crisis management. Since over exposure to mass crises may lead to increased anxiety, stress and various other health-related problems (Garfin et al., 2020), it is ever more important to take steps to help people overcome fear (Malta et al., 2020). In this respect, education campaigns may be launched to promote public health messages (Wang et al., 2020), traditional and social media campaigns to promote mental health and reduce distress (Sher, 2020). Fourth, since it is becoming harder for us to make predictions about the future because of the rapid and unpredictable changes in all areas of our lives, developing skills of tolerance of uncertain and ambiguous situations and learning to live with uncertainties seems to be gaining more importance in almost all fields in today's world. Making long life plans or trying to keep all variables about our lives under control makes no sense anymore. Fifth, some recent experiences worldwide show that massive traumatic life experiences seem to become an inseparable part of life. Mass traumatic events bring adverse psycho-social effects by creating more uncertainty about the future. Thus, it is of great importance to inform people at the right time using appropriate methods directed by governments. At such times, it is of great importance to inform people accurately, as the whispering campaign has a wide reach and there is so much misinformation circulating on social media, that it only causes more fear and intolerance of uncertainty. Thus, as Qiu et al. (2020) suggest, all countries should establish nationwide strategic planning and coordination for psychological support, which may be delivered through telemedicine during pandemic and mass disasters. Furthermore, government or health officials should avoid giving mixed messages that may lead to public confusion, uncertainty and fear at those times (Han et al., 2018). Last, the psychological burden of the pandemic is becoming harder because of the lack of social interaction. For reducing this negative effect to a minimum level, we should find various ways to maintain social connectedness (Baumeister \& Leary, 1995) and keep in touch with family and friends via phone calls or video conferences (Usher et al., 2020).

\section{Limitations}

There are some limitations to this study. First, study data were collected through an online survey and these methods may lead to some concerns over the accurate representation of the target population. Second, women were overrepresented (two thirds of the participants were women). Third, despite the analysis used to examine the effect mechanisms of the variables, this study is descriptive and correlational in nature, so it may not represent true causation among the variables. Last, 
self-administered data collection tools were used for the research, and this may have caused a self-assessment bias.

\section{Conclusion}

This study examined the current situation in the sphere of public mental health in Turkey taking into account select variables during the COVID-19 pandemic. High rates of depression, stress and anxiety symptoms were reported by participants. It has been demonstrated that it is important to develop interventions in terms of developing more tolerance to uncertainty and taking psychological, social and political measures to effectively deal with the outbreak. In this framework, the interventions related to the epidemic should be arranged in a multi-dimensional way. Most of the psychological problems mentioned arise from a social and economic background. It is an important need to take measures to alleviate the economic burden brought on by the epidemic. Carrying out debriefing and training activities for the general population or for different groups, such as children, adults, healthcare workers and elderly people using the television media or through face-toface interaction and providing the appropriate conditions, may be another useful intervention. In this context, addressing the anxiety and fears of individuals and creating CBT-based interventions for them may provide significant relief. Similarly, it may be beneficial to prepare guidelines on the psychological dimensions of the epidemic and its solutions and deliver them to the relevant groups. The joint coordination of different units, such as the ministry of health, the ministry of national education, and the ministry of family and social policies, is important for the healthy and comprehensive implementation of all the above.

\section{Author's ORCID}

Ferhat Kardaş

https://orcid.org/0000-0003-3386-3956

\section{References}

Ahorsu, D. K., Lin, C. Y., Imani, V., Saffari, M., Griffiths, M. D., \& Pakpour, A. H. (2020). The Fear of COVID-19 Scale: Development and initial validation. International Journal of Mental Health and Addiction. https://doi.org/10.1007/s11469-02000270-8

Bakioglu, F., Korkmaz, O., \& Ercan, H. (2020). Fear of COVID-19 and positivity: Mediating role of intolerance of uncertainty, depression, anxiety, and stress. International Journal of Mental Health and Addiction. https://doi.org/10.1007/ s11469-020-00331-y

Baumeister, R. F., \& Leary, M. R. (1995). The need to belong: Desire for interpersonal attachments as a fundamental human motivation. Psychological Bulletin, 117, 497-529.

Bitan, D. T., Grossman-Giron, A., Bloch, Y., Mayer, Y., Shiffman, N., \& Mendlovic, S. (2020). Fear of COVID-19 Scale: Psychometric characteristics, reliability and validity in the Israeli population. Psychiatry Research, 289, 113100. https:// doi.org/10.1016/i.psychres.2020.113100

Boyraz, G., \& Legros, D. N. (2020). Coronavirus disease (COVID-19) and traumatic stress: Probable risk factors and correlates of Posttraumatic Stress Disorder. Journal of Loss and Trauma, 25(6-7), 503-522. https://doi.org/10.1080/1532 $\underline{5024.2020 .1763556}$

Carleton, R. N. (2016). Into the unknown: A review and synthesis of contemporary models involving uncertainty. Journal of Anxiety Disorders, 39, 30-43.

Carleton, R. N., Mulvogue, M. K., Thibodeau, M. A., McCabe, R. E., Antony, M. M., \& Asmundson, G. J. G. (2012). Increasingly certain about uncertainty: Intolerance of uncertainty across anxiety and depression. Journal of Anxiety Disorders, 26(3), 468-479. https://doi.org/10.1016/i.janxdis.2012.01.011

Carleton, R. N., Norton, M. P. J., \& Asmundson, G. J. (2007). Fearing the unknown: A short version 
of the Intolerance of Uncertainty Scale. Journal of Anxiety Disorders, 21(1), 105-117. https://doi. org/10.1016/i.janxdis.2006.03.014

Dsouza, D. D., Quadros, S., Hyderabadwala, Z. J., \& Mamun, M. A. (2020). Aggregated COVID-19 suicide incidences in India: Fear of COVID-19 infection is the prominent causative factor. Psychiatry Research, 290, 11345. https://doi.org/10.1016/i. psychres.2020.113145

Dugas, M. J., Gosselin, P., \& Ladouceur, R. (2001). Intolerance of uncertainty and worry: Investigating narrow specificity in a non-clinical sample. Cognitive Therapy and Research, 25, 551-558. https://doi.org/10.1023/A:1005553414688

Dugas, M. J., Hedayati, M., Karavidas, A., Buhr, K., Francis, K., \& Phillips, N. A. (2005). Intolerance of uncertainty and information processing: Evidence of biased recall and interpretations. Cognitive Therapy and Research, 29, 57-70. https:// doi.org/10.1007/s10608-005-1648-9

Dugas, M. J., Marchand, A., \& Ladouceur, R. (2005). Further validation of a cognitive-behavioral model of generalized anxiety disorder: Diagnostic and symptom specificity. Journal of Anxiety Disorders, 19, 329-343. https://doi.org/10.1016/i. janxdis.2004.02.002

Effati-Daryani, F., Zarei, S., Mohammadi, A., Hemmati, E., Yngyknd, S. G., \& Mirghafourvand, M. (2020). Depression, stress, anxiety and their predictors in Iranian pregnant women during the outbreak of COVID-19. BMC psychology, 8(1), 1-10.

Fergus, T. A. (2013). A comparison of three self-report measures of intolerance of uncertainty: An examination of structure and incremental explanatory power in a community sample. Psychological Assessment, 25(4), 1322-1331. https://doi.apa.org/doi/10.1037/a0034103

Fitzpatrick, K. M., Harris, C., \& Drawve, G. (2020). Fear of COVID-19 and the mental health consequences in America. Psychological Trauma: Theory, Research, Practice, and Policy, 12. https:// psycnet.apa.org/doi/10.1037/tra0000924

Freeston, M., Rhéaume, J., Letarte, H., Dugas, M. J., \& Ladouceur, R. (1994). Why do people worry? Personality and Individual Differences, 17, 791-802.

Garfin, D. R., Silver, R. C., \& Holman, E. A. (2020). The novel coronavirus (COVID-2019) outbreak:
Amplification of public health consequences by media exposure. Health Psychology, 39(5), 355357. http://dx.doi.org/10.1037/hea0000875

Gica, S., Kavakli, M., Durduran, Y., \& Ak, M. (2020). The effect of COVID-19 pandemic on psychosomatic complaints and investigation of the mediating role of intolerance of uncertainty, biological rhythm changes and perceived COVID-19 threat in this relationship: A web-based community survey. Psychiatry and Clinical Psychopharmacology, 30(2), 89-96. doi: 10.5455/PCP.20200514033022

Grupe, D. W., \& Nitschke, J. B. (2013). Uncertainty and anticipation in anxiety: An integrated neurobiological and psychological perspective. Nature Reviews Neuroscience, 14, 488-501. https://doi. org/10.1038/nrn3524

Han P. K., Zikmund-Fisher, B. J., Duarte, C. W. et al. (2018). Communication of scientific uncertainty about a novel pandemic health threat: Ambiguity aversion and its mechanisms. Journal of Health Communication, 23, 435-444. https:// doi.org/10.1080/10810730.2018.1461961

Holaway, R. M., Heimberg, R. G., \& Coles, M. E. (2006). A comparison of intolerance of uncertainty in analogue obsessive-compulsive disorder and generalized anxiety disorder. Journal of Anxiety Disorders, 20(2), 158-174. https://doi. org/10.1016/i.janxdis.2005.01.002

Hollingsworth, D. W., Gauthier, J. M., McGuire, A. P., Peck, K. R., Hahn, K. S., \& Connolly, K. M. (2018). Intolerance of uncertainty mediates symptoms of PTSD and depression in African American veterans with comorbid PTSD and substance use disorders. Journal of Black Psychology, 44(7), 667-688. https://doi.org/10.1177\%2F0095798418809201

Hong, R. Y., \& Cheung, M. W. L. (2015). The structure of cognitive vulnerabilities to depression and anxiety. Clinical Psychological Science, 3, 892-912. https://doi.org/10.1177\%2F2167702614553789

Huang, Y., \& Zhao, N. (2020). Generalized anxiety disorder, depressive symptoms and sleep quality during COVID-19 epidemic in China: A web-based cross-sectional survey. Psychiatry Research, 288, 112954. https://doi.org/10.1101/2 $\underline{020.02 .19 .20025395}$

Kendall, P. C., Norris, L. A., Rabner, J. C., Crane, M. E., \& Rifkin, L. S. (2020). Intolerance of uncertainty and parental accommodation: prom- 
ising targets for personalized intervention for youth anxiety. Current Psychiatry Reports, 22(9). https://doi.org/10.1007/s11920-020-01170-3

Knipe, D., Evans, H., Marchant, A., Gunnell, D., \& John, A. (2020). Mapping population mental health concerns related to COVID-19 and the consequences of physical distancing: A Google trends analysis. Wellcome Open Research, 5, 82-92. https://doi.org/10.12688/wellcomeopenres.15870.2

Levin, J. (2019). Mental health care for survivors and healthcare workers in the aftermath of an outbreak. In Psychiatry of Pandemics (pp. 127141). Springer, Cham.

Lovibond, P. F. \& Lovibond, S. H. (1995). The structure of negative emotional states: Comparison of the Depression Anxiety Stress Scales (DASS) with the Beck Depression and Anxiety Inventories. Behaviour Research and Therapy, 33, 335-343.

Malta, M., Rimoin, A. W., \& Strathdee, S. A. (2020). The coronavirus 2019-nCoV epidemic: Is hindsight 20/20? EClinical Medicine, 20, 100289. https://doi.org/10.1016/j.eclinm.2020.100289

Mamun, M. A., \& Griffiths, M. D. (2020). First COVID-19 suicide case in Bangladesh due to fear of COVID-19 and xenophobia: Possible suicide prevention strategies. Asian Journal of Psychiatry, 51, 102073. https://doi.org/10.1016/i. aip.2020.102073

Mazza, C., Ricci, E., Biondi, S., Colasanti, M., Ferracuti, S., Napoli, C., \& Roma, P. (2020). A nationwide survey of psychological distress among Italian people during the COVID-19 pandemic: Immediate psychological responses and associated factors. International Journal of Environmental Research and Public Health, 17(9), 3165. https://doi.org/10 $3390 / i j e r p h 17093165$

Mertens, G., Gerritsen, L., Duijndam, S., Salemink, E., \& Engelhard, I. M. (2020). Fear of the coronavirus (COVID-19): Predictors in an online study conducted in March 2020. Journal of Anxiety Disorders, 74, 102258. https://doi.org/10.1016/i. janxdis.2020.102258

Mihashi, M., Otsubo, Y., Yinjuan, X., Nagatomi, K., Hoshiko, M., \& Ishitake, T. (2009). Predictive factors of psychological disorder development during recovery following SARS outbreak. Health Psychology, 28(1), 91-100. https://doi.apa.org/ doi/10.1037/a0013674
Ministry of Health, (2020, December 31). COVID-19 information page, general coronavirus table. https://covid19.saglik.gov.tr/EN-69532/general-coronavirus-table.html

Ornell, F., Schuch, J. B., Sordi, A. O., \& Kessler, F. H. P. (2020). "Pandemic fear" and COVID-19: Mental health burden and strategies. Brazilian Journal of Psychiatry, 42(3), 232-235. https://doi. org/10.1590/1516-4446-2020-0008

Pakpour, A. H., \& Griffiths, M. D. (2020). The fear of COVID-19 and its role in preventive behaviors. Journal of Concurrent Disorders. http://irep.ntu. ac.uk/id/eprint/39561

Parlapani, E., Holeva, V., Nikopoulou, V. A., Sereslis, K., Athanasiadou, M., Godosidis, A., ...\& Diakogiannis, I. (2020). Intolerance of uncertainty and loneliness in older adults during the COVID-19 pandemic. Frontiers in Psychiatry, 11, 842. https://doi.org/10.3389/fpsyt.2020.00842

Pierce, M., Hope, H., Ford, T., Hatch, S., Hotopf, M., John, A., ...\& Abel, K. M. (2020). Mental health before and during the COVID-19 pandemic: A longitudinal probability sample survey of the UK population. The Lancet Psychiatry, 7(10), 883-892.

Robichaud, M., \& Dugas, M. J. (2006). A cognitive-behavioral treatment targeting intolerance of uncertainty. In G. C. L. Davey \& A. Wells (Eds.), Worry and its psychological disorders: Theory, assessment and treatment (pp. 289-304). Chichester, UK: Wiley.

Qiu, J., Shen, B., Zhao, M., Wang, Z., Xie, B., \& Xu, $Y$. (2020). A nationwide survey of psychological distress among Chinese people in the COVID-19 epidemic: Implications and policy recommendations. General Psychiatry, 33(2), e100213. http:// dx.doi.org/10.1136/gpsych-2020-100213corr1

Rettie, H., \& Daniels, J. (2021). Coping and tolerance of uncertainty: Predictors and mediators of mental health during the COVID-19 pandemic. American Psychologist, 76(3), 427-437. http:// dx.doi.org/10.1037/amp0000710

Saricam, H. (2018). The psychometric properties of Turkish version of Depression Anxiety Stress Scale-21 (DASS-21) in health control and clinical samples. Journal of Cognitive-Behavioral Psychotherapy and Research, 7(1), 19-30. https:// doi.org/10.5455/JCBPR.274847

Saricam, H., Erguvan, F. M., Akın, A., \& Akca, M. S. (2014). The Turkish short version of the Intoler- 
ance of Uncertainty (IUS-12) Scale: The study of validity and reliability. Route Educational and Social Science Journal, 1(3), 148-157.

Satici, B., Saricali, M., Satici, S. A., \& Griffiths, M. D. (2020). Intolerance of uncertainty and mental wellbeing: Serial mediation by rumination and fear of COVID-19. International Journal of Mental Health and Addiction. https://doi. org/10.1007/s11469-020-00305-0

Shanahan, L., Steinhoff, A., Bechtiger, L., Murray, A. L., Nivette, A., Hepp, U., Ribeaud, D., \& Eisner, M. (2020). Emotional distress in young adults during the COVID-19 pandemic: Evidence of risk and resilience from a longitudinal cohort study. Psychological Medicine, 1-10. https://doi. org/10.1017/s003329172000241X

Sher, L. (2020). The impact of the COVID-19 pandemic on suicide rates. QJM: An International Journal of Medicine, 1-6. https://doi.org/10.1093/ qimed/hcaa202

Shihata, S., McEvoy, P. M., Mullan, B. A., \& Carleton, R. N. (2016). Intolerance of uncertainty in emotional disorders: What uncertainties remain? Journal of Anxiety Disorders, 41, 115-124. https://doi.org/10.1016/i.janxdis.2016.05.001

Solomou, I., \& Constantinidou, F. (2020). Prevalence and predictors of anxiety and depression symptoms during the COVID-19 pandemic and compliance with precautionary measures: Age and sex matter. International Journal of Environmental Research and Public
Health, 17(14), 4924. https://doi.org/10.3390/ ijerph17144924

Taylor, S. (2019). The psychology of pandemics: Preparing for the next global outbreak of infectious disease. Cambridge Scholars Publishing.

Thayer, Z. M., \& Gildner, T. E. (2020). COVID-19-related financial stress associated with higher likelihood of depression among pregnant women living in the United States. American Journal of Human Biology, e23508. https://doi.org/10.1002/ ajhb.23508

Xiong, J., Lipsitz, O., Nasri, F., Lui, L. M., Gill, H., Phan, L., ...\& Mclntyre, R. S. (2020). Impact of COVID-19 pandemic on mental health in the general population: A systematic review. Journal of Affective Disorders. 277(1), 55-64. https:// doi.org/10.1016/i.jad.2020.08.001

Usher, K., Durkin, J., \& Bhullar, N. (2020). The COVID-19 pandemic and mental health impacts. International Journal of Mental Health Nursing, 29(3), 315-318. https://doi.org/10.1111/ inm.12726

Wang, W., Tang, T., \& Wei, F. (2020). Updated understanding of the outbreak of 2019 novel coronavirus (2019-nCoV) in Wuhan, China. Journal of Medical Virology, 92(4), 441-447. https://doi. org $\angle 10.1002$ Ljmv. 25689

Zandifar, A., \& Badrfam, R. (2020). Iranian mental health during the COVID-19 epidemic. Asian Journal of Psychiatry, 51. https://doi.org/10.1016/i. ajp. 2020.101990 